\title{
Lazer e Turismo e a prática do manejo e monitoramento da visitação pública como estratégia de gestão dos recursos no Parque Estadual da Cantareira (SP)
}

\section{Leisure and Tourism and the practice of management and monitoring of public visitation as a resource management strategy in Cantareira State Park (SP, Brazil)}

Cesar Juliano dos Santos Alves, Diego Hernandes Rodrigues Laranja, Sidnei Raimundo

\section{RESUMO}

O presente trabalho teve como objetivo trabalhar com o manejo do sistema de trilhas existentes na Unidade de Conservação e avaliar os diversos impactos causados pela visitação pública no Parque Estadual da Cantareira através da análise de indicadores. Observou-se a escassez de informações adequadas de manejo já realizado; mas por outro lado, permitiu avaliar as variáveis de planejamento efetivo dessas áreas de forma a otimizar o serviço prestado ao público e ao mesmo tempo, minimizando possíveis impactos.

PALAVRAS-CHAVE: Lazer; Turismo; Manejo de Impactos; Unidade de Conservação; Gestão da Visitação Pública.

\section{ABSTRACT}

This study aimed to work with the management of the existing trail system at Protect Area and assess the various impacts from public viewing in the Cantareira State Park through analysis of indicators. We noted the lack of proper information management already done; but on the other hand, enabled to evaluate the effective planning variables of these areas in order to optimize the service provided to the public, and at the same time minimizing potential impacts.

KEYWORDS: Leisure; Tourism; Management of Impacts; Protect Areas, Management of Public Visitation. 


\section{Introdução}

O lazer em ambientes naturais e o desenvolvimento acentuado do ecoturismo são resultados da procura por vivências e experiências em contato com a paisagem natural, como em parques e outras áreas verdes. Em áreas urbanas esse fenômeno é mais complexo devido à quase não existência desses tipos de paisagem.

Nesse contexto, as Unidades de Conservação (UCs) inseridas em áreas metropolitanas adquirem papel de destaque e se tornam grandes potenciais para o desenvolvimento dessas atividades, por guardarem em seus domínios atributos naturais e de beleza cênica, raros numa cidade, que produzem grandes atrativos para serem visitados e contemplados. As UCs que são da categoria Parque Estadual (no caso desse artigo, por se tratar de UCs de domínio Estadual) englobam áreas onde pode-se desenvolver e estruturar Programas de Uso Público, ou seja, atividades e equipamentos que possibilitam esse contato do visitante com os atrativos naturais, através de sistemas de trilhas e estruturas que permitam o uso e a interpretação do ambiente focados, entre outros motivos, na educação ambiental.

Porém, o uso intensivo por parte dos visitantes e mesmo ações naturais, leva a necessidade do manejo adequado de áreas de visitação pública em UCs. O manejo e o monitoramento de impactos tanto do ambiente visitado quanto da experiência do visitante contribuem para uma gestão dos recursos e são ferramentas (técnicas) que as UCs dispõem para sua manutenção.

O presente trabalho apresenta os principais resultados obtidos pelo Projeto "Aprender com Cultura e Extensão" da Pró-reitoria de Cultura e Extensão da Universidade de São Paulo em parceria com o Parque Estadual da Cantareira, gerido pela Fundação para Conservação e Produção Florestal do Estado de São Paulo (Fundação Florestal), autarquia da Secretaria do Meio Ambiente do Estado de São Paulo (SMA/SP). A pesquisa teve como objetivo trabalhar com o manejo do sistema de trilhas existentes na UC e avaliar os diversos impactos causados pela visitação pública no Parque Estadual da Cantareira através da análise de indicadores.

Dessa forma, a partir da descrição do processo de tomada de decisão e possibilitando a avaliação dessas práticas realizadas pela Equipe de Uso Público do núcleo Pedra Grande (um dos Núcleos Administrativos do Parque Estadual da Cantareira), observou-se a escassez de informações adequadas de manejo já realizado, mas por outro lado, permitiu avaliar as variáveis de planejamento efetivo dessas áreas de forma a otimizar o serviço prestado ao público e ao mesmo tempo, minimizando possíveis impactos.

\section{Lazer turismo e manejo do uso público em Unidades de Conservação}

De acordo com o documento do EMBRATUR (1994) que trata das Diretrizes para uma Politica Nacional do Ecoturismo, ao abordar a questão das áreas protegidas, ressalta especialmente os Parques Nacionais, Estaduais ou Municipais, Florestas Nacionais e Áreas de Proteção Ambiental - APAs -, como primeiros destinos ecoturísticos procurados pelos fluxos nacionais e internacionais. 
Os atrativos dessas áreas protegidas devem ser estruturados como núcleos de visitação pública, que, de acordo com o Sistema de Unidades de Conservação (SNUC), tem como objetivo "o desenvolvimento de atividades de educação e interpretação ambiental, de recreação em contato com a natureza e de turismo ecológico" (BRASIL, Lei no 9.985 de 18 de julho de 2000). Essas áreas são importantes para o desenvolvimento de atividades relacionadas ao lazer e turismo em contato com a natureza, sendo objeto de instalação de uma estrutura mínima como trilhas interpretativas e de acesso aos atrativos, centro de visitantes, portaria e outras estruturas que facilitem 0 acesso dos visitantes. Tais estruturas devem ser reguladas de acordo com diretrizes e normas estabelecidas por documentos oficiais como Plano de Manejo ou para UCs que não os possuem, normas dos órgãos ambientais que as regem.

As atividades oferecidas como percurso em trilhas interpretativas ou 0 estudo do meio contribuem para a construção de conhecimentos sobre a fauna, flora, recursos hídricos e as relações entre os seres vivos em geral, sendo procuradas como atividades de ecoturismo e lazer em contato com a natureza (PELICIONI; TOLEDO, 2010). De acordo com estudos do perfil do ecoturista, realizado pela ABETA (2010) há três níveis de envolvimento com a natureza, chamados de contato quando a natureza é vista como algo admirável, intocável, uma espécie de santuário - o foco está na contemplação. Interação, quando o indivíduo vê a natureza como dinâmica, cheia de boas surpresas, disposto a viver esses momentos e não apenas contemplar. O último nível, e que infere maior envolvimento dos visitantes, é a combinação, quando a natureza, as atividades as observações os turistas e as comunidades formam um todo dinâmico, em equilíbrio. Ressalta-se aqui que esta noção de "equilíbrio" diz respeito também a um entendimento sistêmico da natureza, onde homem e natureza podem vir a fazer um todo inseparável. Não se leva em conta nessas abordagens as contradições, conflitos ou problemas decorrentes dessa relação (sociedade $\mathrm{x}$ natureza), pois nesse momento da visitação, as pessoas estão interessadas em diversão e descanso. As informações decorrentes estão associadas à noção de equilíbrio ecossistêmico, do qual o homem pode fazer parte.

A interpretação ambiental é uma das atividades mais desenvolvidas dentro de Parques, por se relacionar tanto com atividades de ecoturismo como com as atividades que envolvem a educação ambiental. A forma como é desenvolvida pode atuar diretamente nesses níveis, trabalhando diretamente com a qualidade da experiência do visitante, sendo comumente utilizadas técnicas como estruturas de placas interpretativas, centro de visitantes e monitores e guias para a prestação de serviço de informação ou de condução dos visitantes.

Porém, com relação ao exercício desse tipo de atividade, Pelicioni e Toledo (2010, p.304) abordam a seguinte questão:

Atividades como essas, com finalidade turísticas ou educativas, estão crescendo e se diversificando a cada dia, e muitos programas de educação ambiental desenvolvidos em áreas naturais têm adotado essa estratégia, priorizando muitas vezes a transmissão de conteúdo de ecologia, 
ciências e biologia, enfatizando apenas 0 'conservacionismo'. Além disso, por não exigirem grandes investimentos econômicos, essas atividades acabam sendo realizadas corriqueiramente também em espaços urbanos de lazer, em finais de semana ou feriados e, na maioria das vezes, por pessoas sem nenhum preparo na área ambiental (PELICIONI; TOLEDO, 2010, p.304).

Essa necessidade de se impor um conteúdo no qual se aborde os elementos constituintes da paisagem e suas relações, muitas vezes é feita sem uma estruturação e objetivos firmados por quem planeja e executa 0 uso público nas ÚCs. Com isso o planejamento e monitoramento da experiência do visitante são fundamentais para entender o perfil e necessidades desse público.

Com relação ao potencial do ecoturismo nas UCs, Passold e Kinker (2010) abordam a necessidade de estimular a visitação pública de maneira a potencializar os benefícios, sem interferir na implementação de outros programas e atividades de manejo e sem ocasionar impactos negativos aos recursos naturais e valores histórico-culturais.

As trilhas são os equipamentos de lazer nas UCs e suas condições são parâmetros que devem ser controlados para atender as necessidades daqueles que as visitam. De acordo com MAGRO (1999) os impactos negativos mais comuns oriundos do uso público são demonstrados pela perda da vegetação e consequente erosão do solo, presença de lixo, contaminação de água, incêndios e distúrbio da fauna. No entanto, avaliar tais condições somente através da perspectiva quantitativa não permite um manejo preocupado com a satisfação dos visitantes e com as oportunidades de recreação. Stankey; Cole (1998) afirmam que a capacidade de carga (CC) não possibilita uma gestão efetiva do turismo nos parques, uma vez que produz resultados relacionados apenas com os processos associados ao uso sem o comprometimento com a experiência do visitante.

Por outro lado o Limits of Acceptable Change ${ }^{1}$ (LAC) preconiza a experiência da visitação como ferramenta essencial para a o manejo das trilhas, através da escolha de indicadores e padrões que expressem condições aceitáveis de mudança. Trilhas que apresentem condições próximas ou ultrapassando seus limites podem prejudicar a qualidade da visitação, a segurança dos visitantes e gerar problemas de degradação ambiental. O método Visitor Impact Management ${ }^{2}$ - VIM (GRAEFE et al., 1990) derivado do LAC, permite identificar, de forma clara, as relações entre indicadores-chave de impacto e os variados aspectos dos padrões de uso da visitação em áreas naturais (PASSOLD et. al 2000). Planejamento e monitoramento inadequados do uso público podem acarretar danos irreparáveis aos ecossistemas e esta deficiência na fiscalização e monitoramento faz com que não haja tempo hábil para a recuperação (SOBRAL, GOMES, SANTOS, 2009). Através do monitoramento de impactos nas trilhas é possível tornar o equipamento mais interessante para o perfil do publico visitante, além de prevenir o gasto excessivo de recursos para o manejo e manutenção e fornecer ao longo do tempo uma importante base de dados para a revisão ou implementação do plano de manejo da UC. 
Dessa forma, o planejamento e o manejo das estruturas existentes, a partir do monitoramento de impactos possíveis de serem causados pela visitação, torna-se uma ferramenta para a gestão eficiente dos recursos repassados para a manutenção das áreas de uso público. Com isso, o planejamento e implantação dessas práticas são componentes necessários às políticas de gestão de Programas de Uso Público de Parques.

Com relação à geração de recursos através da visitação pública, Passold; Kinker (2010) relacionam a atividade do ecoturismo e os impactos gerados da seguinte forma:

\begin{abstract}
Embora seja um dos objetivos das UCs oferecer aos visitantes a oportunidade de vivenciar a natureza conservada, e embora esta seja uma possibilidade de geração de recursos financeiros, a visitação gera impactos e aumenta os custos operacionais da unidade. [...] Os técnicos têm muito mais trabalho sem ter um retorno a curto prazo.' Isto, em parte, ocorre porque a maioria dessas áreas não tem autonomia financeira, visto que os recursos gerados são remetidos para uma conta central do governo e as decisões referentes ao orçamento são feitas de forma centralizada e não atendem às reais necessidades de custeio (PASSOLD; KINKER, 2010, p.405-406).
\end{abstract}

Algumas metodologias para o monitoramento vem sendo discutidas e utilizadas, porém o profissional de turismo necessita de ferramentas práticas para efetiva implementação, como a determinação da capacidade de suporte ou outras ferramentas como environmental impact assessment (EIA), limits of acceptable change (LAC), visitor impact management (VIM) e visitor experience and resouce protect (VERP), entre outras técnicas, que trabalham em interface entre várias metas e valores (WIGHT, 1998).

Para o presente trabalho, optou-se pela técnica VIM por ter sido a técnica julgada mais adequada e sistematizada pela Fundação Florestal, órgão gestor das unidades de conservação paulistas. Esta Fundação elaborou, a partir de suas experiências, o "Manual de monitoramento e gestão dos impactos da visitação" cujo objetivo foi apresentar e sistematizar os procedimentos do VIM como ferramenta prática e aplicável a todas as UCs do Estado de São Paulo.

De acordo com Wight (1998), a metodologia do VIM envolve uma coleção de dados de diferentes estratégias de gestão de impactos num processo sequencial visando a redução ou controle de impactos que ameaçam a qualidade das áreas de lazer e turismo ao ar livre e a experiência do visitante nelas. Esse processo sequencial se dá a partir de 8 passos que requerem dois elementos distintos: descrição (da relação entre condições específicas do uso e os impactos associados a essa condição) e avaliação (da aceitação dos vários impactos). O VIM pode ser adaptado com outras metodologias e ou utilizado em áreas urbanas de turismo de massa. 


\section{Visitação Pública e o Parque Estadual da Cantareira - Núcleo Pedra Grande}

O Parque Estadual da Cantareira (PEC) localiza-se na Zona Norte do município de São Paulo, possuindo quatro núcleos estruturados para a visitação pública, contendo atrativos de grande valor paisagístico, como os naturais, formados pela Serra recoberta pela floresta em bom estado de conservação e histórico-culturais, ligados às primeiras tecnologias de captação de água datadas do inicio do século XX. Os núcleos para visitação são: Pedra Grande, Engordador, Águas Claras e Cabuçu.

O núcleo Pedra Grande, objeto de estudo do presente trabalho, foi estruturado em 1989, foi o primeiro aberto à visitação e possui como principal atrativo o Mirante da Pedra Grande, afloramento rochoso granítico intrusivo, com 1010 metros de altitude, possibilitando ao visitante observar a paisagem urbana em contraste com a paisagem serrana, e perceber 0 ambiente através de uma valoração do impacto humano e suas consequências na modificação da paisagem natural.

A visitação pública ocorre aos finais de semana e feriados, sendo no período de dezembro, janeiro e julho aberto de terça a domingo. As trilhas existentes nos núcleos de visitação são autoguiadas, contendo cada núcleo portaria com a cobrança de ingressos. O núcleo Pedra Grande possui a maior visitação dos núcleos. A Figura 1 mostra a distribuição da visitação ao longo de maio de 2009 a abril de 2010, contando a partir da vigência da publicação da Portaria Normativa FF/DE no 074/2009, que trata sobre a cobrança de ingressos nos Parques Estaduais do Estado de São Paulo, tendo uma visitação média de 2.363 ao mês. Um padrão clássico de temporada de visitação, quando normalmente a alta temporada está associada aos meses de férias e verão não é observada no P.E. Cantareira. O mês de dezembro de 2010 é o de menor fluxo de visitante e o de maio de 2009, o de maior fluxo. Pode-se inferir, a partir destes dados, que o visitante desta UC é caracterizada pelo predomínio de turistas, mas por visitantes da própria Região metropolitana de São Paulo, que o visita em seu tempo livre ou disponível (de folga).

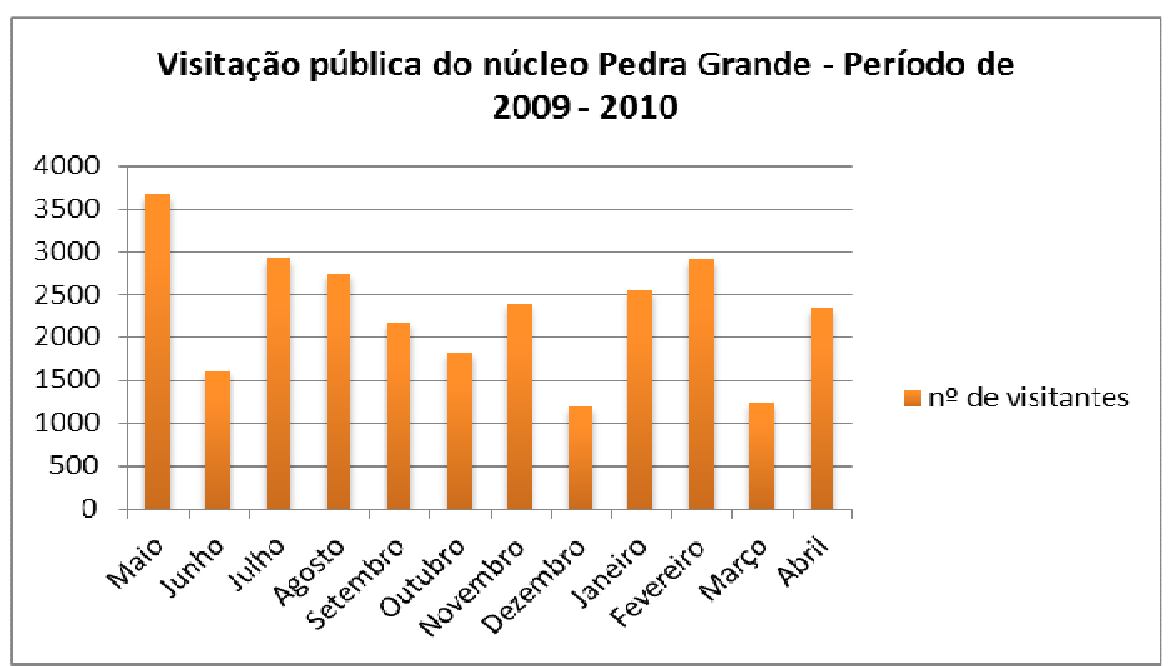

Figura 1: Sazonalidade da visitação pública no núcleo Pedra Grande. Figure 1: Seasonality of public visitation at the Núcleo Pedra Grande. 
No período de segunda a sexta feira, os núcleos possuem programas de agendamento para o atendimento a escolas e grupos realizando roteiros de interpretação ambiental monitorados. O atendimento é realizado de acordo com a procura de tais grupos, tendo o enfoque maior em escolares, com um limite de atendimento de 40 pessoas por período (correspondendo a um grupo), tendo o máximo de atendimento de 80 pessoas/dia. Cabe destacar que este número está associado à capacidade de manejo efetiva da atividade, ou seja, dos monitores disponíveis para condução de grupos nas trilhas.

O núcleo Pedra Grande possui um sistema de trilhas, sendo a Trilha da Pedra Grande a principal, que possui um trajeto total de 9,5 $\mathrm{Km} \mathrm{e}$ possibilita o acesso ao Mirante da Pedra Grande, e mais a frente ao Lago das Carpas, onde o visitante pode praticar atividades como piquenique e descanso, preparando-se para a volta, que é realizada pelo mesmo trajeto da ida. Existe também a trilha da Bica e das Figueiras que possuem trajetos menores de $1,0 \mathrm{~km}$ a $1,5 \mathrm{~km}$, que apresentam como atrativos principais a bica d'água, representando os mananciais e a Figueira-Branca (Ficus sp) representando um exemplar da flora imponente e fundamental na interação com a fauna. A Figura 2 mostra o sistema de trilhas existentes no núcleo Pedra Grande.

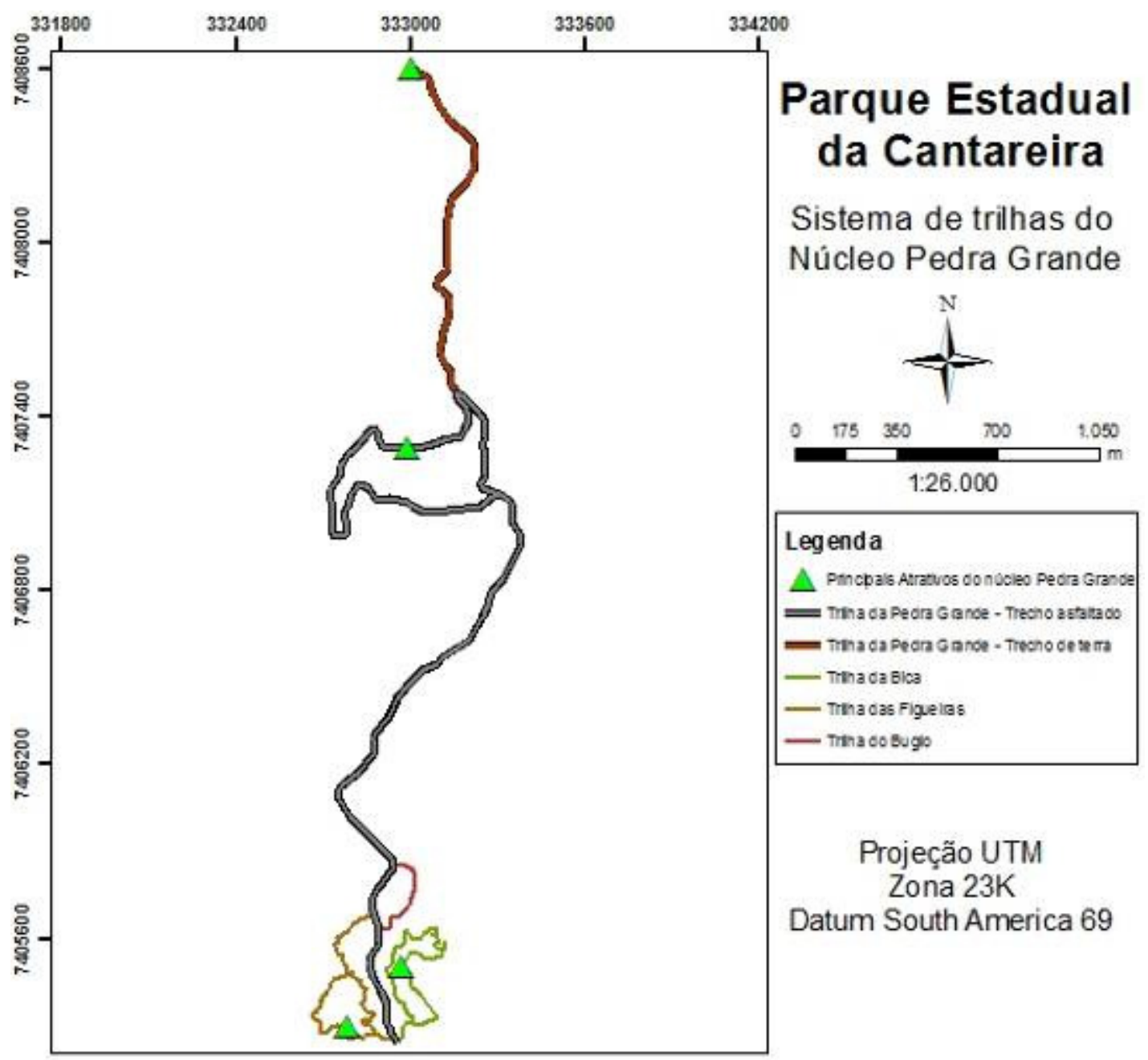

Figura 2: Sistemas de trilhas do núcleo Pedra Grande.

Figure 2: Tracks systems of the núcleo Pedra Grande. 
A Trilha da Pedra Grande, por ser uma trilha de longo percurso com aspecto de estrada, de acordo com Alves; Raimundo (2009) facilita a caminhada ou a prática da corrida, que atrai visitantes para uma vivência prolongada na paisagem natural. $O$ atrativo final desta trilha é a Pedra Grande, da qual se pode avistar a cidade e permite ao visitante oriundo de áreas urbanas a exercitar sua cognição, sensibilizando-se com o contraste do natural com o urbano, a través da prática de lazer em contato com a natureza. Com isso, a utilização da Trilha da Pedra Grande é realizada de forma intensa, sendo o propósito dos visitantes que frequentam o núcleo aos finais de semana.

As trilhas da Figueira e da Bica localizam-se próximas à entrada do núcleo, sendo trilhas com piso de terra, com características fechadas, sendo a interpretação ambiental trabalhada de forma mais intensa a partir de placas interpretativas. A Trilha da Bica tem uma utilização maior com grupos agendados no meio da semana, utilizada com pouca frequência pelos visitantes no final de semana. Nessa trilha foi desenvolvido seu conteúdo para o projeto "Criança Ecológica", da Secretaria do Meio Ambiente do Estado de São Paulo, que tem seu público-alvo crianças de 8 a 10 anos de idade. E a Trilha das Figueiras tem sua utilização associada a Trilha da Pedra Grande, no retorno desta. Existe também a trilha do Bugio, que possui um trajeto de $330 \mathrm{~m}$ em forma de ferradura, usada também na volta dos visitantes, porém não estudada nesse projeto, por existir a intensão de adaptá-la para uso de portadores de necessidades especiais.

A seguir, apresentam-se as etapas de trabalho, para se estabelecer 0 manejo da visitação na Unidade de Conservação.

\title{
Trabalhos Preliminares para o Manejo e Monitoramento de Impactos da Visitação Pública
}

Antes de começar os trabalhos de manejo e monitoramento, foi realizada uma pesquisa de normas e diretrizes que indicassem tal necessidade no núcleo. A Resolução Estadual SMA no 059 é uma delas, que em seu artigo 12, aborda essa necessidade da seguinte forma:

\begin{abstract}
A manutenção e melhoria das trilhas e atrativos nas Unidades de Conservação deverão ser realizadas periodicamente, para controlar e reduzir os impactos negativos ao meio físico e biótico advindos da visitação, aumentando a segurança e conforto do visitante (SMA, 2008).
\end{abstract}

As demais diretrizes pesquisadas estão dispostas dentro do Plano de Manejo do PEC, o qual indica ações de monitoramente para trilhas da Zona de Uso Extensivo, sendo recomendada a seguinte ação: 
Todas as trilhas e atrativos presentes nesta zona devem fazer parte de um programa de monitoramento dos impactos causados pela visitação, que não se restrinja somente ao estudo da capacidade de carga (SÃO PAULO, 2009, p.242).

No capítulo referente ao Programa de Uso Público do Plano de Manejo, são feitas observações sobre a carência de estratégias de planejamento, manejo e monitoramento e conservação dos sistemas de trilhas, ressaltando a não existência de um programa integrado de manejo e manutenção, sendo realizadas intervenções de acordo com critérios próprios, de acordo com prioridades e necessidades (SÃO PAULO, 2009). Tal diagnóstico revela a existência do manejo, porém não existe um sistema ou um programa específico para esse manejo, acontecendo frequentemente a necessidade de reparos emergenciais ou problemas de obstrução de trilhas, que às vezes, impedem $\mathrm{O}$ uso constante das trilhas. A partir da revisão bibliográfica e das normas e diretrizes, considerou-se alguns aspectos para a efetivação de um programa de manejo e monitoramento de impactos da visitação de forma sistematizada no PEC, colocados a seguir:

- Recomendações do Plano de Manejo;

- Necessidade de manejo no sistema de trilhas;

- Existência de Programa de Monitoramento proposto pela Fundação Florestal e necessidade de adaptá-lo a realidade do PEC;

- Despender aporte de recursos financeiros de forma eficiente;

- Planejamento com finalidade a minimizar ações emergenciais.

A partir dessa constatação, foi elaborado pela Equipe de Monitores Ambientais do Núcleo Pedra Grande, um plano de trabalho de um ano, a partir de agosto de 2009 para realizar o diagnóstico, manejo e monitoramento do sistema de trilhas, sendo também avaliado ao final desse período o método aplicado em campo e o desenvolvimento das atividades. Tal Equipe atua como responsáveis nessa área, sendo a mesma que planeja e executa as ações de Uso Público, com apoio das outras equipes existentes (manutenção, segurança e outros funcionários).

Foi diagnosticada, a partir do trabalho com o grupo de Monitoria Ambiental, a realização de atividades como a manutenção das trilhas e atrativos do PEC, o atendimento ao programa de Educação Ambiental tanto interno como externo e o atendimento ao público aos finais de semana e feriados. A Tabela 1 mostra as principais funções e atribuições a partir da observação da atuação desses profissionais no núcleo Pedra Grande. 
Tabela 1: Atividades e atribuições da Equipe de Monitores Ambientais do PEC.

Table 1: Activities and Assignments Team Environmental Monitors of the PEC.

\begin{tabular}{|c|c|}
\hline \multicolumn{2}{|c|}{$\begin{array}{l}\text { Atividades } \\
\text { Equipe de Monitores Ambientais }\end{array}$} \\
\hline $\begin{array}{l}\text { Manejo e manutenção das } \\
\text { trilhas e atrativos do PEC }\end{array}$ & $\begin{array}{l}\text { - Manutenção de infraestrutura (degraus, pontes } \\
\text { corrimões) } \\
\text { - Manutenção e elaboração de placas de } \\
\text { informação/interpretação } \\
\text { - Manutenção e correção de piso (erosão, valas de } \\
\text { drenagem) }\end{array}$ \\
\hline $\begin{array}{l}\text { Atendimento ao Programa } \\
\text { de Educação Ambiental }\end{array}$ & $\begin{array}{l}\text { - Organização e agendamento semestral do } \\
\text { Programa de atendimento às escolas/grupos } \\
\text { - Monitoramento de escolas/grupos agendados no } \\
\text { meio da semana } \\
\text { - Elaboração de ações de educação ambiental para } \\
\text { a comunidade do entorno }\end{array}$ \\
\hline Atendimento ao público & $\begin{array}{l}\text { - Prestação de informações sobre o PEC aos finais } \\
\text { de semana } \\
\text { - Elaboração de exposições e ações em datas } \\
\text { relacionadas com o meio ambiente } \\
\text { - Oferecimento de apoio aos demais serviços no final } \\
\text { de semana (fiscalização, autorizações e outros) }\end{array}$ \\
\hline
\end{tabular}

Cada núcleo possui um coordenador de Equipe de Monitores Ambientais, que atua no comando das ações dos Monitores e nas diretrizes dos programas de Uso Público e também é o interlocutor junto à direção do PEC. As ações que envolvem manejo das trilhas também são realizadas pela Equipe de Manutenção do núcleo Pedra Grande, que possui um diálogo permanente com a Equipe de Monitores Ambientais. Estes, por realizarem com frequência caminhadas nas diversas trilhas do núcleo, são os mais habilitados para diagnosticar possíveis áreas que necessitem da atuação imediata da equipe de Manutenção, como árvores caídas ou com risco de queda próximo às áreas de uso dos visitantes, áreas para poda ou com necessidade de corte raso nas áreas de visitação, problemas com a drenagem ou manutenção das estruturas edificadas (banheiros e centro de visitantes).

\section{Diagnóstico preliminar para o manejo e nova formulação da interpretação ambiental}

O diagnóstico levou em consideração os principais pontos de necessidade de manejo, como sistema de drenagem, mudança de traçado e melhoria das informações das placas interpretativas. A seleção de prioridades nas trilhas baseou-se a partir dos seguintes critérios colocados a seguir:

1 - Necessidade de corrigir situações preocupantes. Por exemplo, conserto de trechos desmoronados, intransponíveis, ao longo de um penhasco, ou remoção de barreiras caídas numa seção íngreme;

2 - Necessidade de corrigir problemas que estão causando danos importantes à trilha, como erosão; 
3 - Restauração da trilha de acordo com os padrões planejados no projeto de implantação (quando houver). A facilidade em encontrar a trilha e andar por ela deve harmonizar-se com as especificações projetadas para o cenário recreacional, e com os objetivos dos usuários levados em conta no projeto. As providências podem ir desde simplesmente acrescentar sinais de orientação ao longo do caminho, a um total remanejamento de trechos mal projetados, no caso de uma trilha que esteja toda erodida.

Qualquer que seja a prioridade deve-se providenciar a manutenção da trilha, tão logo perceba a necessidade, para prevenir danos mais graves e mais dispendiosos no futuro (SÃO PAULO, 2008, p. 14).

O diagnóstico e o planejamento foram realizados em duas das trilhas existentes no núcleo, a Trilha da Bica e Figueiras, por possuírem um leito de terra, e os impactos físicos serem mais frequentes, e também possuírem um uso diferenciado da Trilha da Pedra Grande, que não é uma trilha propriamente, mas uma estrada asfaltada. A partir desse diagnóstico de necessidades emergenciais, foram feitos cronograma de manejo para ambas as trilhas, levando em consideração o quadro atual de funcionários, a aquisição de materiais para o manejo e as outras atividades já exercidas no programa de Uso Público.

A Trilha da Bica apresentou como principais necessidades: a abertura e a manutenção de valas de drenagem, reformulação de alguns trechos, sendo um deles feito um traçado em zigue-zague para suavizar a declividade, e reforma das estruturas, como pontes e corrimões, sendo algumas já realizadas por planejamentos anteriores. Por serem trilhas autoguiadas, é utilizada com frequência uma comunicação visual, como placas, para expor conteúdos de interpretação ambiental dentro das trilhas. Porém, é constante 0 encontro de placas que contém informações interpretativas de forma biocêntrica, muitas delas apenas com a identificação da espécie (normalmente da flora) e seu nome científico. Essa forma, comumente utilizada em UCs, expõe informações de uma maneira não cativante ao olhar do visitante. Esse tipo de comunicação visual deve buscar ser produzida de forma entretida, tentando responder a duas perguntas: "por quê?" e "para quê ?" (HAM, 1992).

As placas confeccionadas para a trilha da Bica tiveram como foco em informações abordadas no projeto "Criança Ecológica". As informações contidas foram elaboradas para contemplar além de conteúdos trabalhados ao longo da trilha, sensações e informações que tragam ao visitante assimilação das relações existentes no meio ambiente visitado e sua importância de conservação. A Figura 3 mostra umas das placas confeccionadas pelos monitores ambientais para a Trilha da Bica, utilizando prancha de madeira, pirógrafos para demarcar as palavras. A placa relaciona uma das espécies da fauna da região, o Bicho-Preguiça (Bradypus variegatus), dificilmente observado pelos visitantes, colocada ao lado de uma das espécies da flora com a qual ele interage, a Embaúba (Cecropia sp). Também foi confeccionada uma ilustração pintada com tinta acrílica, com a intenção de torná-la mais atraente ao visitante. 


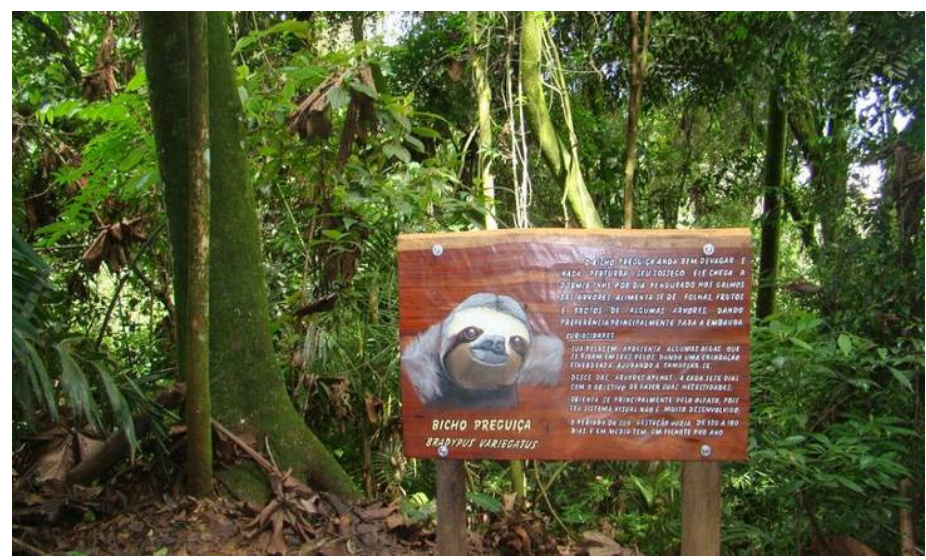

Figura 3: Placa interpretativa implantada na trilha da Bica. Fonte: Acervo PEC (2009). Figure 3: Plate deployed interpretive in trilha da Bica. Source: Collection PEC (2009).

$\mathrm{Na}$ trilha das Figueiras, as principais necessidades diagnosticadas foram: a abertura de valas de drenagem ou a manutenção das mesmas, mudança da inclinação de algumas partes da trilha, reajustando as bordas críticas do traçado e a reformulação e confecção de novas placas interpretativas. Em alguns trechos com necessidades de criação de barreiras de contenção ou plataformas para elevação do piso em curvas, foram utilizados materiais lenhosos encontrados próximos ao traçado da trilha. A utilização de materiais encontrados na própria trilha permite soluções práticas para o manejo e possibilita maior adequação da estrutura com a paisagem (SÃO PAULO, 2008). Também foram projetadas novas placas interpretativas para a trilha, utilizando a mesma metodologia da Trilha da Bica, porém, sem o vínculo com o projeto "Criança Ecológica". Para estabelecer o conteúdo das mesmas, a Equipe de Monitoria decidiu privilegiar informações que conduzam ao entendimento de algum processo ou interação do ecossistema. A pintura e o desenho ilustrativo contidos nas placas também foram feitas com o intuito de se tornar visível, chamativa e atraente. A Figura 4 mostra uma das placas implantadas na Trilha das Figueiras, tratando sobre o Palmito Juçara (Euterpe edullis), considerado uma espécie-chave da flora, que sofre ameaças de extração irregular em diversos locais e o Tucano-de-bico-verde (Ramphastos dicolorus) que é uma das aves avistada frequentemente alimentando-se do seu fruto.

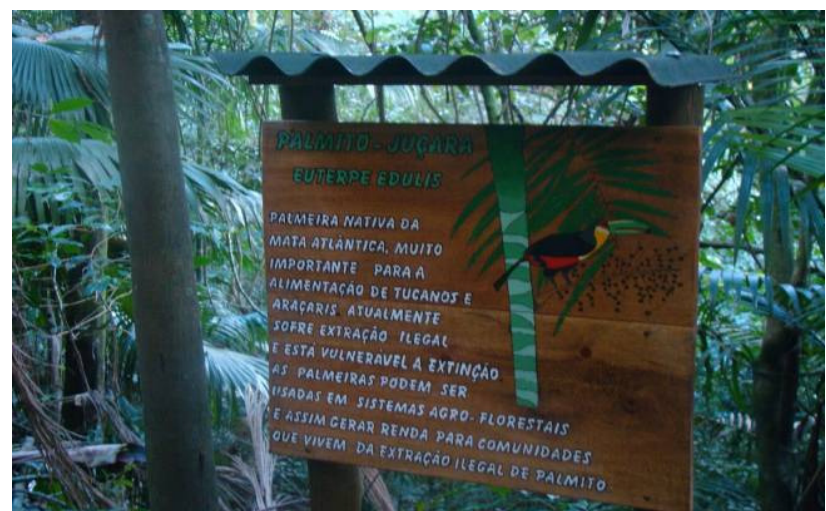

Figura 4: Placa interpretativa implantada na Trilha das Figueiras.

Fonte: Diego Laranja (2009).

Figure 4: Plate deployed interpretative in Trilha das Figueriras.

Source: : Diego Laranja (2009). 
O manejo das trilhas, com base no diagnóstico emergencial, foi feito gradativamente, de acordo com cronograma já estipulado, possibilitando o monitoramento dos impactos a trabalhar de modo preventivo a partir da avaliação periódica do sistema de trilhas.

\section{Monitoramentos dos impactos da visitação}

A metodologia utilizada, indicadores de impacto e os padrões iniciais escolhidos para a avaliação e comparação foram os mesmos propostos no Plano de Monitoramento e Gestão dos Impactos da Visitação (SÃO PAULO, 2009, p.31-42). O plano foi elaborado pela Gerência de Ecoturismo da Mata Atlântica/Fundação Florestal, e constitui um programa desenvolvido nas UCs existentes no Estado de São Paulo, que possuem uso público.

Para a aplicação da metodologia em campo foram escolhidos no máximo 10 pontos amostrais em cada trilha, sendo anotadas as informações e observações em cada ponto e censo e em uma planilha de monitoramento elaborada pelo plano supracitado. Em seguida os dados foram comparados com os padrões de mudanças aceitáveis já estabelecidos, Os indicadores, seus padrões aceitáveis e os resultados da coleta de dados estão dispostos na Tabela 02 abaixo:

Tabela 2: Análise dos dados de monitoramento coletados no sistema de Trilhas da Pedra Grande.

Table 2: Analysis of the monitoring data collected at the Trilhas da Pedra Grande system.

\begin{tabular}{|l|c|c|c|c|c|c|c|}
\hline \multirow{3}{*}{ Trilhas } & \multicolumn{7}{|c|}{ Indicadores } \\
\cline { 2 - 8 } & $\begin{array}{c}\text { Largura } \\
\text { da } \\
\text { trilha } \\
(\mathrm{m})\end{array}$ & $\begin{array}{c}\text { Presença } \\
\text { de Lixo } \\
(\%)\end{array}$ & $\begin{array}{c}\text { Danos a } \\
\text { infra- } \\
\text { estrutura } \\
(\%)\end{array}$ & $\begin{array}{c}\text { Comporta- } \\
\text { mento } \\
\text { animal (\%) }\end{array}$ & $\begin{array}{c}\text { No de } \\
\text { trilhas } \\
\text { não } \\
\text { oficiais } \\
(\%)\end{array}$ & $\begin{array}{c}\text { Problemas } \\
\text { de } \\
\text { drenagem } \\
(\%)\end{array}$ & $\begin{array}{c}\text { Danos aos } \\
\text { recursos } \\
\text { naturais } \\
(\%)\end{array}$ \\
\cline { 2 - 8 } & $10 \%$ & $10 \%$ & $10 \%$ & $5 \%$ & $10 \%$ & $10 \%$ & $10 \%$ \\
\hline $\begin{array}{l}\text { Pedra } \\
\text { Grande }\end{array}$ & ------- & $90 *$ & 50 & 20 & 40 & ------- & 30 \\
\hline Bica & 1,70 & 60 & 0 & 0 & 30 & 60 & 30 \\
\hline Figueiras & 1,21 & 40 & 0 & 0 & 40 & 90 & 20 \\
\hline
\end{tabular}

${ }^{\star}$ Resultado difere da opinião do visitante

Cada indicador foi avaliado em fevereiro a maio, de acordo com o término do manejo de cada trilha, dando início à composição de um histórico de monitoramento de impactos da visitação no núcleo Pedra Grande.

\section{Experiência dos visitantes}

Para a complementação dos dados, foi realizada a aplicação do questionário de avaliação da experiência dos visitantes. Tal questionário possui todos os indicadores analisados nas trilhas e tem como objetivo identificar a percepção da situação encontrada a partir do olhar dos visitantes, tentando diagnosticar sua experiência e se a presença do impacto, sendo negativa, influencia no desenvolvimento da sua atividade dentro do núcleo. Os indicadores avaliados estão descritos a seguir: 
- Danos aos recursos naturais;

- Danos ás estruturas;

- Trilhas;

- Limpeza;

- Infraestrutura e serviços;

- Numero de visitantes.

Foram aplicados 50 questionários no período de Julho de 2010, sendo o dobro recomendado pela metodologia, devido ao Núcleo Pedra Grande ter uma visitação média alta em relação a outros Parques Estaduais do Estado de São Paulo. O resultado dos questionários foram somados com uma primeira amostragem de 14 questionários realizada em abril, totalizando 64 questionários aplicados no $1^{\circ}$ semestre de 2010 . Em cada indicador o visitante pode avaliar em uma escala de valores composta por ruim, aceitável, boa ou excelente a condição encontrada no núcleo. No total, a avaliação por parte dos visitantes mostrou um adequação com o encontrado dentro do núcleo, estando dentro de um padrão de valores boa e excelente a maioria das respostas. Porém, para alguns visitantes, algumas questões como a simples presença de lixo na borda da trilha foi obtido um resultado negativo na experiência, mesmo a manutenção do Núcleo ter sido bem avaliada, a atribuição do impacto foi feita ao mau comportamento por parte de outros visitantes.

Outras questões que apareceram foram o manejo com corte de algumas espécies de árvores, como o Pinheiro-do-Paraná (Araucaria angustifolia) que se localizam no primeiro trecho de subida da Trilha da Pedra Grande, que devido ao intenso período de chuva ocasionado de dezembro de 2009 a março de 2010, alguns exemplares ofereceram perigo de queda. Porém, as evidências de corte desses exemplares e também de algumas árvores caídas nas trilhas trouxeram impactos na experiência dos visitantes.

Com relação à infraestrutura do núcleo, as estruturas sanitárias e algumas construções antigas foram diagnosticadas por alguns visitantes, gerando um impacto não satisfatório em alguns casos. A parte de informação das trilhas, como sistema de placas indicativas e interpretação ambiental da Trilha da Pedra Grande foram indicadas diversas vezes gerando algumas dúvidas no caminho a ser tomado, principalmente próximo ao quilômetro 2,5 de subida, quando o visitante tem a opção de ir ao Mirante da Pedra Grande passando abaixo da mesma, percorrendo um percurso maior ou seguir em frente, percorrendo um percurso menor. A questão da sinalização foi um dos critérios mais observados pelos visitantes, inclusive das placas não serem bilíngues. Abaixo, a Tabela 3 sistematiza as principais observações que influenciaram os visitantes, a partir das respostas dos questionários:

Com relação ao nível de experiência da visitação tendo as variáveis valorativas: comum, previsível, satisfatório, marcante e inesquecível, foi avaliado de forma positiva tendo o nível marcante e inesquecível como principais respostas dos questionários. Foi observado na aplicação que grande parte dos entrevistados que responderam com alto grau de 
satisfação são frequentadores do núcleo há algum tempo, sendo a experiência gerada através das várias visitas um fator que acentuou a escolha dos níveis marcante e inesquecível.

Tabela 3: Observações realizadas a partir da aplicação dos questionários aos visitantes.

Table 3: Observations made from the questionnaires to visitors.

\begin{tabular}{|c|l|}
\hline \multicolumn{2}{|c|}{ Experiência dos visitantes } \\
\hline \multirow{4}{*}{$\begin{array}{c}\text { Observações } \\
\text { realizadas pelos } \\
\text { visitantes }\end{array}$} & $\begin{array}{l}\text { Evidências de corte/manejo com uso de ferramentas } \\
\text { cortantes (facões, motossera etc.); }\end{array}$ \\
\cline { 2 - 2 } & $\begin{array}{l}\text { Uso de motocicletas para fiscalização nas trilhas de uso } \\
\text { público; }\end{array}$ \\
\cline { 2 - 2 } & Presença de lixo em pequena quantidade; \\
\cline { 2 - 2 } & Condições inadequadas da infraestrutura dos sanitários; \\
\cline { 2 - 2 } & Problemas de drenagem; \\
\cline { 2 - 2 } & Má sinalização e falta de placas interpretativas. \\
\hline
\end{tabular}

\section{Conclusões}

A metodologia adotada a partir do "Manual de Monitoramento de Impactos da Visitação" demonstra-se prática na utilização em campo, com um sistema de aplicação simples, com o intuito de se obter um histórico do monitoramento de impactos da visitação públicas nas UCs do Estado de São Paulo. Porém, após a aplicação da metodologia no Núcleo Pedra Grande, pode-se observar uma série de ajustes que a metodologia deva enfrentar para se adequar a realidade do uso e da gestão existente, sendo os padrões para cada indicador questionados em algumas oportunidades.

Devido a essa padronização da metodologia, existem restrições quanto ao número de pontos amostrais e censos possíveis de serem demarcados nas trilhas, que totaliza 10 pontos no máximo, devido à sistematização das planilhas de monitoramento, que não permite a extrapolação desses pontos. Com isso, a Trilha da Pedra Grande foi dividida em nove pontos amostrais, sendo que cada censo possui $1 \mathrm{~km}$, tornando-o extenso a distância dos pontos para a proposta metodológica. Assim, a coleta de dados para o monitoramento se ateve em evidências encontradas no censo em cada ponto, utilizando da observação de campo para a complementação dos dados e possíveis explicações sobre a causa de algum impacto encontrado.

A partir dessa alteração, identificaram-se alguns indicadores com uma extrapolação dos padrões aceitáveis, que na sua maioria é colocado $10 \%$ dos pontos amostrais, porém na prática, tal indicador não apresentou necessidade de manejo, mostrando a necessidade da revisão de seus padrões. 


\section{Referências bibliográficas}

ABETA/MinTur (Associação Brasileira de Empresas de Ecoturismo e Turismo de Aventura / Ministério do Turismo, Brasil). Perfil do turista de aventura e do ecoturista no Brasil. São Paulo: ABETA, 2010, 96p.

BRASIL, Empresa Brasileira de Turismo. Diretrizes para uma política nacional de ecoturismo. Brasília: EMBRATUR, 1994.

LECHNER, L. Planejamento, implantação e manejo de trilhas em Unidades de Conservação. Curitiba, Paraná, Fundação o Boticário de Proteção à Natureza, ano 03, ํo 03, 2006.

PASSOLD, A.J.; KINKER, S.M.S. Visitação sustentável em Unidades de Conservação. In: PHILLIPI JUNIOR, A.; RUSCHMANN, D.V.M. (Org). Gestão ambiental e sustentabilidade no turismo. Barueri, São Paulo: Manole, 2010, p. 383-416.

FREIXÊDAS-VIEIRA, V.M.; PASSOLD, A.J.; MAGRO, T.C. Impactos do Uso Público: um guia de campo para utilização do método VIM. In: Congresso Brasileiro de Unidades de Conservação, 2., campo grande, 2000. Anais do... Campo Grande: Rede Nacional Pró Unidade De Conservação E Fundação O Boticário De Proteção À Natureza, 2000. p. 296-305.

KUSS, F.R.; GRAEFE, A.R.; VASKE, J.J. Visitor Impact Management - A Review of Research. Washington, D.C., National Parks and Conservation Association, 256p., (V.1) 1990.

MAGRO, T.C. Impactos do uso público em uma trilha no planalto do Parque Nacional do Itatiaia. 133 p. Tese (Doutorado) - Escola de Engenharia de São Carlos, Universidade de São Paulo, 1999.

PELICIONI, M. C. F.; TOLEDO, R. F. Educação para o turismo: turistas e comunidade. In: PHILLIPI JUNIOR, A.; RUSCHMANN, D.V.M. (Org). Gestão ambiental e sustentabilidade no turismo. Barueri, São Paulo: Manole, 2010, p. 301-312.

SÃO PAULO (Estado). Secretaria do Meio Ambiente. Manual de construção e manutenção trilhas. São Paulo: SMA, 2009, p. 171.

SÃO PAULO (Estado). Secretaria do Meio Ambiente. Manual plano de monitoramento e gestão dos impactos da visitação. São Paulo; SMA, 2009.

SÃO PAULO (Estado). Secretaria do Meio Ambiente. Plano de Manejo de Unidade de Conservação. Parque Estadual da Cantareira. São Paulo: Instituto Florestal/Fundação Florestal, 2009. 539p.

SOBRAL, I.S.; GOMES, L.J.; SANTOS, J. Proposta de monitoramento dos impactos do ecoturismo no Parque Nacional Serra de Itabaiana, Sergipe. Revista Nordestina de Ecoturismo, Aracaju, v.2, n.1, p.6-24, 2009.

WIGHT, P. Tools for sustainability analysis in planning and managing tourism and recreation in the destination. In: HALL, C.M.; LEW, A.A. (Org.). Sustainable tourism: a geographical perspective. Harlow, United Kingdom: Pearson Education, 1998, p. 75-91. 


\section{Notas: \\ ${ }^{1}$ Limite aceitável de câmbio, ou mudança. \\ ${ }^{2}$ Manejo do Impacto da Visitação.}

Cesar Juliano dos Santos Alves: Universidade de São Paulo - EACH, São Paulo, SP, Brasil.

E-mail: cesar.jsalves@gmail.com

Link para o currículo Lattes: http://lattes.cnpq.br/3259740918548632

Diego Hernandes Rodrigues Laranja: Universidade Federal de São Carlos, Sorocaba, SP, Brasil.

E-mail: diegolaranja@gmail.com

Link para o currículo Lattes: http://lattes.cnpq.br/8392515335621317

Sidnei Raimundo: Universidade de São Paulo - EACH, São Paulo, SP, Brasil.

E-mail: sraimundo@usp.br

Link para o currículo Lattes: http://lattes.cnpq.br/0352060547192132

Data de submissão: 09 de maio de 2014

Data de recebimento de correções: 20 de outubro de 2014

Data do aceite: 20 de outubro de 2014

Avaliado anonimamente 